\title{
The use of Ammi visnaga in the treatment of prediabetes and weight loss: the antioxidant impacts in diabetes treatment as a new medical hypothesis
}

\begin{abstract}
Introduction: Prediabetes status is considered as an important feature in either controlling the development or progression of diabetes. It may pass unnoticed because the symptoms of diabetes are usually not well established.

Study objectives: The main objectives of the present study were to explore the efficacy of using Ammi visnagain treating pre-diabetic cases and weight losing.

Methods and subjects: A prospective study was conducted to investigate the impact of using Ammi visnaga treatment of pre-diabetes and weight control. The study included 5 patients with pre-diabetes (glucose level was $128 \pm 32 \mathrm{mg} / \mathrm{dl}$ ). The age of patients was $42 \pm 18.5$ years. The study included 3 males and 2 females. In general, patients were overweight according to body mass index level was $28 \pm 7.8 \mathrm{~kg} / \mathrm{m}^{2}$. The patients used the aqueous extract of $A m m i$ visnaga for two months (200 $\mathrm{ml}$ daily).
\end{abstract}

Results: At the end of the experiment, the glucose level was significantly reduced $(p<0.05)$ to the level of $88 \pm 12.5 \mathrm{mg} / \mathrm{dl}$. There was also a significant reduction in the level of BMI from $28 \pm 7.8 \mathrm{~kg} / \mathrm{m}^{2}$ to $22 \pm 6.4 \mathrm{~kg} / \mathrm{m} 2(\mathrm{p}<0.05)$.

Conclusion: The results of the present study showed that Ammi visnaga has the therapeutic potential to control the progression of complete episodes of diabetes by controlling the pre-diabetic status

Keywords: pre-diabetes, glucose, BMI, overweight, Ammi visnaga
Volume 10 Issue $6-2020$

\begin{abstract}
Ahed J Alkhatibi,2
'Department of Legal Medicine, Toxicology and Forensic Medicine, Jordan University of Science \& Technology, Jordan ${ }^{2}$ Department of medicine and critical care, department of philosophy, Academician secretary of department of Sociology, Jordan
\end{abstract}

Correspondence: Ahed J Alkhatib, Department of Legal Medicine, Toxicology and Forensic Medicine, Jordan University Of Science \& Technology, Jordan, Tel 00962795905।45, Email ajalkhatib@just.edu.jo,drahedalkatib@yahoo.com

Received: October II, 2020 | Published: November 09, 2020
Abbreviations: ADA, American diabetes association; BMI, body mass index

\section{Introduction}

At the worldwide level, the predominance of type 2 diabetes has drastically expanded. ${ }^{1-3}$ Examination has demonstrated a huge connection among diabetes and every one of heftiness and insulin obstruction just as adjustments in the capacity of $\beta$-cells in the pancreas. ${ }^{4,5}$ The subsequent impacts incorporate declining paces of insulin digestion, for example, glucose, lipids, and proteins. ${ }^{6}$ Diabetes can bring about regulatory changes in the hemostasis of calcium, phosphorus and magnesium finishing with genuine confusions including cardiovascular sickness and neurological problems ${ }^{7,8}$ As indicated by the American Diabetes Association (ADA), pre-diabetes can be characterized as either impedance of fasting glucose (5.6$6.9 \mathrm{mmol} / \mathrm{L}$ ) or alteration of oral glucose tolerance test (2-h OGTT glucose $7.8-11.0 \mathrm{mmol} / \mathrm{L}){ }^{9}$ Different investigations indicated that the pre-diabetic state is described by a decrease of glucose tolerance and lowered insulin secretion. ${ }^{10}$ It has been exhibited that the condition of pre-diabetes is related with creating cardiovascular occasions, for example, myocardial anomalies. Appropriately, as ahead of schedule as the cardiovascular changes have been resolved in this express, the outcomes are ideal in forestalling the advancement of heart illnesses. ${ }^{11}$

\section{Study objectives}

The main objectives of the present study were to explore the therapeutic potential of Ammi visnagain treating pre-diabetic cases and lowering weight.

\section{Methods and subjects}

Study design: A prospective study was conducted to examine the impact of using Ammi visnaga on patients with pre-diabetes. All participants in the present study voluntarily participated, and agreed to use this prescription with weekly monitoring for their glucose levels. No nutritional restrictions were followed.

Study sample: Study sample included 5 patients with prediabetes, 2 females and 3 males.

Study procedure: Patients were suggested to use the aqueous extract of Ammi visnaga, $200 \mathrm{ml} /$ daily for two months. At the beginning and the end of the experiment, in addition to weakly monitoring of glucose levels were taken, the BMI was calculated for each patient.

Statistical analysis: The analysis of data was carried out using SPSS version 21. Descriptive statistics were used to describe data. The collected data was presented in terms of means and standard deviation. The relationships between variables was determined based on independent $T$ test. Significance was considered at $\alpha \leq 0.05$.

\section{Results}

As demonstrated in Table 1, the mean age of the patients was $42 \pm 18.5$ years, $60 \%$ of patients were males. The mean level of glucose was $128 \pm 32 \mathrm{mg} / \mathrm{dl}$. The mean of BMI was $28 \pm 7.8 \mathrm{~kg} / \mathrm{m}^{2}$. As seen in Table 2, there were significant changes in the levels of glucose and BMI. Glucose levels significantly decreased from $128 \pm 32 \mathrm{mg} / \mathrm{dl}$ to $88 \mathrm{mg} / \mathrm{dl}(\mathrm{p}<0.05)$. The levels of BMI were significantly decreased $(\mathrm{p}<0.05)$ from $88 \pm 7.8$ to $22 \pm 6.4 \mathrm{~kg} / \mathrm{m}^{2}$. 
Table I Study variables in the beginning of the study

\begin{tabular}{ll}
\hline Variable & Description \\
\hline Age $(M \pm S D)$ years & $42 \pm 18.5$ years \\
Gender $(\mathrm{N}, \%):$ & \\
- Male & $3(60 \%)$ \\
- Female & $2(40 \%)$ \\
Glucose $(M \pm S D) \mathrm{mg} / \mathrm{dl}$ & $128 \pm 32$ \\
BMl $(M \pm S D) \mathrm{kg} / \mathrm{m}^{2}$ & $28 \pm 7.8 \mathrm{~kg} / \mathrm{m}^{2}$
\end{tabular}

Table 2 The relationships between study variables before and after the experiment

\begin{tabular}{llll}
\hline Variable & M & SD & P value \\
\hline Glucose-before & 128 & 32 & $<0.05$ \\
Glucose-after & 88 & 12.5 & \\
BMl-before & 28 & 7.8 & $<0.05$ \\
BMl-after & 22 & 6.4 & \\
\hline
\end{tabular}

\section{Discussion}

We have previously shown that pre-diabetic conditions can be treated and reversed to physiological level using rat models by the using of Urtica pillifera. ${ }^{12}$ We also found that pre-diabetes can be reversed by the using of tadalafil $5 \mathrm{mg} /$ daily. ${ }^{13}$ The present study showed that another herbal treatment, Ammi visnaga, can be used to treat pre-diabetic conditions. We think that it can exert their effects by two mechanisms. The first mechanism is mediated through the antioxidant's effect. ${ }^{14}$ The second mechanism is through decreasing lipid levels such as cholesterol and triglycerides as reported in other studies. ${ }^{15}$ Using rat model, we previously found that molecular defects in the brain white matter were beyond the events involved in the development of diabetes. ${ }^{16}$ We also found similar effects on liver induced by anti-oxidants. ${ }^{17}$ The impacts of using Ammi visnaga in reducing weight were apparent in significantly lowering the levels of BMI. BMI is a good indicator of health since it determines normal weight, overweight, and obesity. ${ }^{18}$

\section{Conclusion}

The present study demonstrated that pre-diabetes is a very important situation and can be controlled to prevent the development of full episodes of diabetes, and it can be reversed to physiological conditions. Ammi visnaga is a herb with therapeutically beneficial effects to control diabetes.

\section{Study limitations}

The study gave a clue to early control diabetes, but the number of participants limited the possibility of generalizing the results. Other limitations included investigating other biochemical tests including lipid profile, liver function tests, and kidney function tests.

\section{Acknowledgments}

None.

\section{Conflicts of interest}

Author declare that there is no conflict of interest.

\section{Funding}

None.

\section{References}

1. Shaw JE, Sicree RA, Zimmet PZ. Global estimates of the prevalence of diabetes for 2010 and 2030. Diabetes Res Clin Pract. 2010;87:4-14.

2. Unwin N, Gan D, Whiting D. The IDF Diabetes Atlas: providing evidence, raising awareness and promoting action. Diabetes Res Clin Pract. 2010;87(1):2-3.

3. Skovso Sos. Modeling type 2 diabetes in rats using high fat diet and streptozotocin. J Diabetes Invest. 2014;5:349-358.

4. Guilherme A, Virbasius J, Vishwajeet P, et al. Adipocyte dysfunction linking obesity to insulin resistance and type 2 diabetes. Nat Rev Mol Cell Biol. 2008;9(5):367-377.

5. Wang Lianzi, Tao Li, Liu Jiaqing, et al. Association between glycosylated hemoglobin A1c and bone biochemical markers in type 2 diabetic postmenopausal women: a cross-sectional study. BMC Endocrine Disorders. 2019;9:31.

6. Steven E Kahn, Halban PA. Release of incompletely processed proinsulin is the cause of the disproportionate proinsulinemia of NIDDM. Diabetes. 1997;46:1725-1732.

7. Zakeri Z, Azizi Z, Mehrabifar H, et al. Evaluation of bone mineral density in premenopausal women with type-2 diabetes mellitus in Zahedan, Southeast Iran. J Pak Med Assoc. 2011;61(5):443-445.

8. AG, Jaganathan J, Philip R, Soman RR, et al. Evaluation of bone mineral density among type 2 diabetes mellitus patients in South Karnataka. $J$ Nat Sci Biol Med. 2017;8(1):94-98.

9. Katulanda GW, Katulanda P, Dematapitiya C, et al. Plasma glucose in screening for diabetes and pre-diabetes: how much is too much? Analysis of fasting plasma glucose and oral glucose tolerance test in Sri Lankans. BMC Endocrine Disorders. 2019;19:11.

10. Renner S, Fehlings $C$, Herbach N, et al. Glucose intolerance and reduced proliferation of pancreatic beta-cells in transgenic pigs with impaired glucose dependent insulinotropic polypeptide function. Diabetes. 2010;59:1228-1238.

11. Nunes S, Soares E, Fernandes J, et al. Early cardiac changes in a rat model of prediabetes: brain natriuretic peptide overexpression seems to be the best marker. Cardiovascular Diabetology. 2013;12:44.

12. Amawi KF, Alkhatib AJ. Urtica Pilulifera in Treating Pre-diabetic Rat Model to Control the Blood Glucose, Lipids and Oxidative Stress. Medical archives (Sarajevo, Bosnia and Herzegovina). 2020;74(3):168171

13. Ahed J Alkhatib. Prediabetes can be Reversed Using Low Dose Tadalafil: Non- Classical Treatment of Diabetes as A New Medical Hypothesis. Archives of Diabetes \& Obesity. 2020;2(5).

14. Khalil N, Bishr M, Desouky S, et al. Ammi Visnaga L., a Potential Medicinal Plant: A Review. Molecules. 2020;25:301.

15. Bhagavathula AS, Mahmoud Al-Khatib AJ, Elnour AA, et al. Amm Visnaga in treatment of urolithiasis and hypertriglyceridemia. Pharmacognosy research. 2014;7(4):397-400.

16. Al-khatib A. Co-expression of iNOS and HSP70 in diabetes type 1 makes a rational hypothesis to explain the diabetic neuropathy. European Scientific Journal. 2013;9(3):145-156.

17. Amawi KF, Al-Mazari IS, Alsarhan A, et al. Diabetes upregulates the expression of HSP90 and downregulates HSP70 in the liver of diabetic rats. Comp Clin Pathol. 2019;28:473-478.

18. Adult BMI Calculator 